\title{
O jogo "Eu Autônomo" como um instrumento de reflexão para a aprendizagem de línguas estrangeiras
}

\author{
Walkyria Magno e Silva \\ Universidade Federal do Pará \\ walkyriamagno@gmail.com \\ Fernanda Souza e Silva \\ Universidade Federal do Pará \\ f.souza.fr@gmail.com
}

\section{Resumo}

Autonomia na aprendizagem de línguas é essencial para o desenvolvimento da competência em língua estrangeira. Impossível aprender uma língua sem executar, de forma contínua, ações que vão muito além daquelas demandadas por um professor. No entanto, organizar metacognitivamente o processo de autonomização sempre foi um desafio para grande parte dos estudantes. Tassinari (2015) propõe um modelo que visa auxiliar nesse processo. Este artigo, além de discutir as bases individuais do processo de autonomização, transforma o modelo proposto em um jogo a ser executado coletivamente. O texto mostra como isso foi feito e os resultados de um emprego experimental desse em uma turma de aprendentes de níveis diferentes. Os resultados mostram que houve uma maior conscientização, por parte dos estudantes, do que significa aprender uma língua e quais as diferentes dimensões que precisam ser mobilizadas para que essa aprendizagem seja eficiente.

Palavras-chave: autonomia; conscientização do processo de aprendizagem; aprendizagem de línguas estrangeiras.

\begin{abstract}
Being autonomous is fundamental for competence development in a foreign language. It is impossible to learn another language without continuous actions that go way beyond the ones commanded by a teacher. However, metacognitively organizing the autonomization process has always been a challenge to most students. Tassinari (2015) proposes a model that aims at helping students in this process. This article, besides discussing the individual basis of the autonomization
\end{abstract}


process, transforms Tassinari's model into a game to be collectively played. It shows how this was done and the results of an experimental round played by a group of freshmen with different levels of command in the foreign language. Results show that there was a higher level of awareness among students concerning on one hand what really means learning a language and on the other which are the dimensions that need to be activated in order to achieve successful learning.

Keywords: autonomy; learning process awareness; foreign languages learning.

\section{Introdução}

Desde a década de 1980, com os estudos de Holec (1981), a questão da autonomia dos aprendentes de línguas estrangeiras tem permeado a área da Linguística Aplicada. Isso se reflete na grande quantidade de publicações e pesquisas sobre o assunto. Benson (2001 $\left.{ }^{1}\right)$ condensa as principais correntes de pensamento sobre o tema em um volume que serviu como impulso a uma nova fase nesses estudos. Hoje, já não se considera autonomia como aprender sozinho, mas sim saber direcionar seus esforços para uma autodeterminação do caminho a percorrer, dentro dos percalços e propiciamentos ${ }^{2}$ oferecidos pelo ambiente.

Compreendendo a autonomia como um processo socialmente construído, mas individual no seu desenvolvimento, coloca-se a questão de como saber se alguém está se tornando mais autônomo ou não. Mensurar se a reflexão sobre os inumeráveis aspectos que influenciam a aprendizagem, colaborando para que essa seja mais eficaz, é tarefa das mais difíceis. Há inúmeros testes de estratégias de aprendizagem disponíveis, mas nem sempre o estudante que utiliza uma variada gama de estratégias é necessariamente mais autônomo, pois ele pode utilizar poucas delas e essas se mostrarem as mais eficazes.

${ }^{1}$ A segunda edição, publicada em 2011, já substitui certos conceitos tais como níveis de controle por dimensões de controle, reforçando a complementariedade entre os diversos conceitos envolvidos na autonomia.

${ }^{2}$ Propiciamento é a tradução aceita para o termo affordances (VAN LIER, 2004), o qual significa a percepção de algo disponível ao indivíduo, a sua interpretação como algo que favorece suas intenções e a ação desenvolvida a partir disso, geralmente resultando em uma aprendizagem. 
É nessa lacuna que este texto se insere. Primeiramente expomos nossa visão do que seja autonomia. Em seguida detalhamos a questão brevemente lançada no parágrafo anterior sobre a avaliação do progresso dessa capacidade, terminando com a descrição do modelo proposto por Tassinari (2015,) que visa a auxiliar os aprendentes em seu caminho da autonomização. A próxima seção descreve o método utilizado por uma das autoras, que empregou um jogo adaptado do modelo descrito em uma turma de calouros de Letras - Língua Inglesa, visando a despertá-los para a aprendizagem autônoma. A seção que se segue apresenta e discute os resultados de dois estudantes dessa turma, provendo exemplos de processos de autonomização em desenvolvimento. Finalmente, concluímos o texto com alguns direcionamentos que estão sendo seguidos no aprimoramento do jogo, ao mesmo tempo em que argumentamos pela sua utilização como um instrumento de reflexão.

\section{Autonomia}

No lugar de autonomia, um substantivo que dá a ideia de estado, preferimos compreender essa construção como um processo, utilizando-nos do termo autonomização. Compreendemos a autonomização como um sistema dinâmico, adaptativo e complexo. Não estamos sós nessa compreensão. Tatzl (2016) defende uma visão sistêmica da autonomia por acreditar que ela não pode ser considerada um traço individual e isolado, mas sim uma característica emergente gerada em contextos sociais. Segundo esse autor, a autonomia emerge das interações entre o indivíduo e os demais sistemas com os quais se relaciona, o que inclui, entre outros, seus professores, colegas, materiais e contextos.

Ao publicar sua definição de autonomia em 2001, Benson já antevia essa "virada sistêmica" quando afirma que a autonomia é uma "capacidade multidimensional que vai assumir diferentes formas para diferentes indivíduos, ou até para o mesmo indivíduo em diferentes contextos ou períodos" ${ }^{\prime 3}$ (BENSON, 2001, p. 47). Benson e Cooker (2013) corroboram esse pensamento, reconhecendo a variabilidade dessas

\footnotetext{
3 "Multidimensional capacity that will take different forms for different individuals, and even for the same individual in different contexts or at different times".
} 
habilidades. Eles acrescentam que a autonomia afirma a identidade múltipla do indivíduo ao mesmo tempo em que é desenvolvida por meio da interdependência na interação com os outros.

A partir dessas colocações, verifica-se que o comportamento autônomo sofre influência de diferentes fatores - internos e externos - e precisa ser estimulado e mantido continuamente. A autonomia, portanto, não tem um caráter previsível ou se enquadra em uma relação de causa e efeito, pois um mesmo fator pode favorecer um comportamento autônomo em um aluno e reprimi-lo em outro. Da mesma forma, um aprendente autônomo em um determinado contexto pode não o ser em outro. Essas características de abertura a diferentes influências, de dinamismo e da capacidade de se coadaptar - em decorrência tanto das condições iniciais quanto do retorno recebido durante o processo - conferem à autonomia 0 status de um sistema complexo.

Paiva (2006, p. 88-89) está em consonância com essa compreensão quando afirma que

autonomia é um sistema sócio-cognitivo complexo, que se manifesta em diferentes graus de independência e controle sobre o próprio processo de aprendizagem, envolvendo capacidades, habilidades, atividades, desejos, tomadas de decisão, escolhas, $e$ avaliação tanto como aprendiz de língua ou como seu usuário, dentro ou fora da sala de aula.

Franco (2014, p.65) também se filia a essa concepção complexa de autonomia, descrevendo-a como:

um sistema adaptativo complexo, subsistema da aprendizagem, que expressa o dinamismo de um aprendiz que, através de constante auto-organização do sistema, consegue manter ativas as interações com diversos outros componentes da aprendizagem. Em outras palavras, um aprendiz autônomo, à luz do paradigma da complexidade, é aquele que sempre busca interagir, por meio de suas próprias escolhas, com outros elementos que propiciam a aprendizagem. 
Assim, a autonomia se caracteriza por ser um processo, não um produto; ela é mutante, sensível ao contexto. Sua construção é social, embora percorra uma trajetória individual.

\section{Avaliação da autonomização}

Benson (2001/2011) indica que não se pode mensurar a autonomia, mas sim verificar quais comportamentos autônomos são demonstrados pelos estudantes. Esses comportamentos podem ser verificados e atestados como manifestações de autonomia. Costumamos avaliar que, quando o aluno faz algo para sua aprendizagem que ele não foi instado a fazer, ele está exercendo sua autonomia. Julgamos importante reiterar junto a nossos alunos que descrevam e reflitam sobre esses comportamentos, que aprendam a defini-los, descrevê-los e verificar o que aprenderam com eles. No entanto, ainda assim, é difícil fazer com que os alunos reflitam, pois geralmente não sabem por onde começar, não são habituados a pensar em tudo o que a aprendizagem de uma língua adicional pode envolver.

Tassinari (2015) propôs um modelo dinâmico da aprendizagem autônoma no qual o próprio aluno pode acompanhar e fomentar o desenvolvimento de sua autonomia. Esse modelo explicita dimensões interligadas, representadas pelas diferentes cores, conforme aparecem na figura 01 .

Figura 01 - Modelo dinâmico da aprendizagem autônoma

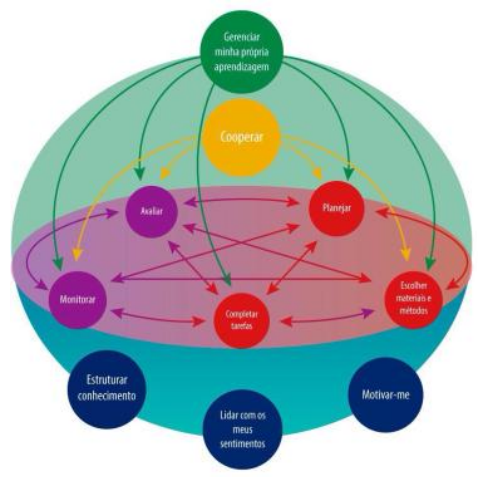

Fonte: Tassinari $(2015$, p. 74) 
O jogo "Eu Autônomo" como um instrumento de reflexão...

Note-se que as dimensões não são hierarquicamente posicionadas. Com exceção da área verde (gerenciar minha própria aprendizagem), que é o processo de autonomização em si, todas as demais dimensões influenciam-se mutuamente. O círculo amarelo (cooperar) abrange aspectos sociais, entendidos como fatores fundamentais na visão atual de autonomização, já que muitas vezes comportamentos autônomos são desenvolvidos, presencial ou virtualmente, na interação com colegas, com professores, com conselheiros em aprendizagem de línguas. Essa dimensão influencia todas as fases executivas da aprendizagem, aqui representadas no espaço central do modelo, em púrpura e em vermelho. As ações de planejar, escolher materiais e métodos, completar tarefas, monitorar e avaliar podem ser executadas tanto sozinho quanto em colaboração com outros agentes.

As esferas na base do modelo são importantes para todo o processo e para cada uma das ações executivas simultaneamente. A todo momento, iterativamente, a estruturação do conhecimento está ocorrendo. Esse modelo abrange os aspectos afetivos da aprendizagem (lidar com meus sentimentos), dando especial atenção à ansiedade, à vergonha e à frustração, por vezes inerentes ao processo, e à capacidade de se automotivar nesse processo longo e, por vezes, penoso que é o da aprendizagem de uma nova língua.

A autora sugere que o modelo seja utilizado por alunos e por conselheiros linguageiros na autoavaliação ou avaliação dos comportamentos autônomos a fim de que reflitam e regulem seu próprio processo de aprendizagem.

Cada um dos componentes desse modelo dinâmico é especificado por meio de macro e micro descritores em listas de checagem que cobrem as principais áreas da aprendizagem autônoma. No total, são 118 descritores, por meio dos quais os alunos podem refletir sobre seu próprio processo de autonomização. Essas listas de descritores não são exaustivas e terminam com um espaço em branco no qual os usuários do modelo podem complementar com outras ações de aprendizagem que lhes ocorram e que sejam significativas para eles. A autora acrescenta que, para que essa reflexão seja bem-sucedida, é necessário que os alunos escolham em que aspecto da sua aprendizagem autônoma gostariam de focar, partindo de suas próprias prioridades, necessidades, objetivos e interesses. Essa liberdade de escolha é um primeiro passo para conscientizá-los sobre seu processo de aprendizagem. A imagem do modelo de Tassinari, cujas setas 
multidirecionais evidenciam as relações entre os diversos componentes do sistema, demonstra a complexidade e dinamicidade típicas do processo de autonomização, abrindo-se a possibilidade de escolhas feitas pelos próprios alunos.

Ao tomar conhecimento desse modelo e compreendê-lo melhor, o grupo de pesquisa do qual as autoras deste texto fazem parte resolveu criar um jogo nele baseado que pudesse ser utilizado em sala de aula e em centros de autoacesso. O objetivo do jogo é fazer com que os alunos percorram o processo de autonomização juntamente com colegas e pessoas mais experientes que os ajudem a alavancar o processo. A elaboração desse jogo será descrita na próxima seção.

\section{Método}

O conceito de jogo está intrinsecamente relacionado à ideia de diversão e lazer. Jogamos para nos divertir, para passar tempo, para confraternizar com amigos e - por que não? - para aprender.

A utilização de jogos, como estratégia de ensino tem se multiplicado em disciplinas, tais como matemática, química, português, entre outras, e as línguas estrangeiras não fogem à regra. Em geral, buscase, por meio desse recurso, levar os alunos a mobilizar conhecimentos construídos em sala de aula na resolução de desafios reais necessários para "ganhar a partida". No âmbito das línguas estrangeiras, por exemplo, com a implementação de jogos, promove-se o desenvolvimento de competências linguageiras em situações próximas à realidade nas quais

[...] o aprendiz tem um contexto e uma razão plausível para conectar conhecimentos prévios com informações novas - necessárias ao jogo - e, assim, se apoderar de determinado conteúdo linguístico de forma duradoura (KASDORF, 2013, p.16).

A constatação da eficácia dessas atividades lúdicas, tanto no desempenho linguageiro quanto no aumento da motivação dos aprendentes, está no cerne da construção do jogo "Eu autônomo". Pretende-se, com esse jogo, levar os jogadores a objetivar, refletir e resolver problemas relacionados não ao objeto da aprendizagem - a língua estrangeira -, mas às estratégias e aos métodos que utilizam na construção dessa aprendizagem. 
O jogo foi construído em três etapas: a) Tradução do modelo de Tassinari; b) Criação do layout do jogo; c) Elaboração de regras e instrumentos. A primeira etapa foi realizada em conjunto com dois outros colegas pesquisadores, que participaram da tradução do modelo, e com os membros do grupo de pesquisa que revisaram a tradução .

$\mathrm{Na}$ etapa de definição do layout do jogo foi criado um baralho de cartas, composto de: a) Uma carta-guia: contendo a descrição da dimensão; b) Um conjunto de cartas de descritores, sendo uma carta para cada macrodescritor, podendo ou não ser especificado por microdescritores; c) Uma carta em branco para sugestões de novos descritores pelos jogadores.

Para autoavaliação de cada microdescritor, o usuário escolhe uma entre três opções de respostas, a qual desencadeará a discussão e consequente reflexão sobre o processo de aprendizagem. São elas: "Eu consigo fazer isso", "Eu quero aprender isso" e "Isso não é importante para mim”. Para o jogo, essas afirmações foram acompanhadas ou substituídas por emoticons, como vemos na imagem abaixo.

Figura 02 - Exemplo de carta

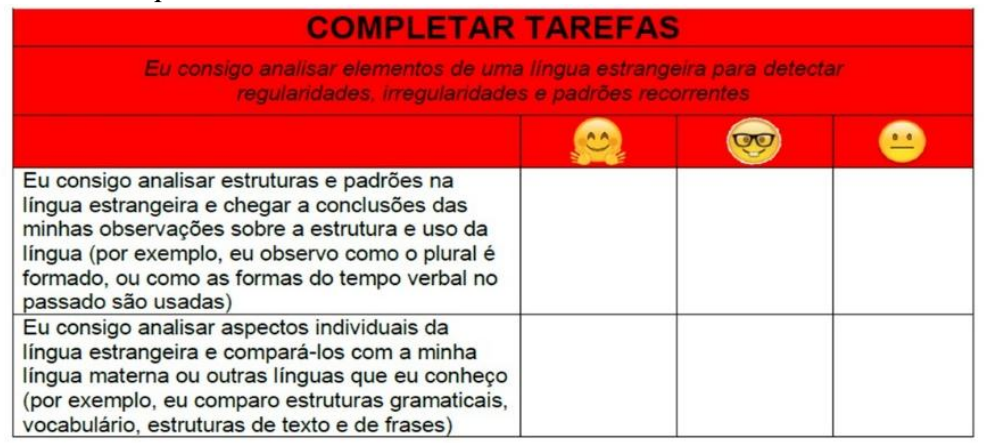

Fonte: as autoras

Além das cartas, também foi produzido um banner com a figura do modelo dinâmico para proporcionar aos jogadores uma visão holística das relações estabelecidas entre as dimensões do jogo. Esse banner é levado ao ambiente em que se está jogando, seja a sala de aula ou um centro de autoacesso. Ele pode ser disposto no chão ou pendurado em um suporte na parede.

A etapa de elaboração das regras do jogo foi orientada por questionamentos como: qual será a dinâmica do jogo? Como produzir um 
jogo que cative os jogadores fazendo com que eles se interessem pelo jogo? Com quem os participantes interagirão? Como será essa interação? Com que objetivo? Como os participantes acompanharão o seu desempenho no jogo? Como saberão se os objetivos estão sendo atingidos?

Primeiramente, constatamos que, no que tange à dinâmica do jogo, poderíamos seguir as instruções sugeridas por Tassinari (2015) para o uso do modelo em centros de autoacesso, quais sejam: são os jogadores que decidem por qual dimensão iniciar a partida e são eles que decidem se, nas próximas rodadas, continuam na mesma categoria até esgotarem as suas cartas ou se migrarão para outra.

O papel do conselheiro linguageiro com quem originalmente o usuário do modelo deveria discutir o resultado de sua autoavaliação, é desempenhado, a exemplo dos Role Playing Games (RPG), por um mestre, que pode ser um professor, um funcionário ou voluntário - no caso dos centros de autoacesso - ou um jogador mais experiente. O mestre é responsável por observar as regras, manter o bom andamento do jogo, provocar reflexões, fazer com que todos no grupo se manifestem e orientar os jogadores na solução de eventuais problemas que eles não consigam resolver sozinhos.

A primeira rodada consiste na apresentação do modelo e na explicação dos objetivos e do funcionamento do jogo. Isso feito, iniciam-se as partidas, que seguem a seguinte dinâmica:

1) Os jogadores escolhem a dimensão que gostariam de jogar;

2) São formados grupos específicos para cada dimensão e distribuídos os respectivos baralhos;

3) Cada integrante do grupo recebe uma carta cujos descritores deve ler em voz alta, autoavaliar-se, utilizando uma das três afirmações: "Eu consigo fazer isso", "Eu quero aprender isso" e "Isso não é importante para mim”, justificando sua resposta. Em seguida, ele lança o mesmo questionamento aos outros componentes do grupo que, por sua vez, devem proceder da mesma maneira;

4) A rodada continua até que o tempo estipulado para a partida se acabe. O tempo sugerido para a duração de cada rodada é de uma hora.

Para que cada aprendiz acompanhe o seu desempenho no jogo foram elaborados dois instrumentos: uma ficha de rodada (anexo A) e uma 
narrativa de conclusão de dimensão (anexo B). Cada jogador pode tomar notas na sua ficha de rodada ao longo da partida. Ao final da rodada, o jogador deve fazer nessa ficha um resumo das reflexões realizadas no grupo do qual fazia parte, mencionando aquilo que ele já fazia (e como o fazia), o que quer aprender (e o que vai fazer para atingir esse objetivo) e o que não é importante para ele (bem como o porquê disso). A narrativa de conclusão de dimensão deve ser produzida quando o jogador concluir uma delas. Em seu texto, ele relata como o jogo contribuiu para sua aprendizagem e como ele acha que contribuiu para a aprendizagem dos colegas.

Fichas e narrativas são compiladas em um Portfólio de Avaliação da Aprendizagem Autônoma $\left(\mathrm{PA}^{3}\right)$ ou em um Caderno de Avaliação da Aprendizagem Autônoma $\left(\mathrm{CA}^{3}\right)$, registrando, assim, a trajetória percorrida pelo aluno rumo à autonomia. Como um dos problemas recorrentes no processo de autonomização é saber se o aprendiz está ou não gradativamente assumindo o controle pela sua aprendizagem, esse registro (que pode ser virtual ou físico) servirá para cada um (e, se for o caso, para um professor ou um conselheiro linguageiro) verificar retrospectivamente se aquilo que foi planejado para ser feito (principalmente o item "o que quer aprender a fazer") está sendo efetivado.

Uma vez elaborado, o jogo foi pilotado por uma das autoras deste texto em uma turma da disciplina "Aprender a aprender línguas estrangeiras", da Licenciatura em Letras - Língua Inglesa, de uma universidade do norte do Brasil no quarto período letivo de 2017.

$\mathrm{Na}$ primeira aula, os alunos foram instados a escrever suas narrativas de aprendizagem. Assim que todos entregaram essa narrativa, a professora também disponibilizou a sua para os alunos. Em seguida, foi feita uma discussão em sala sobre os fatores que influenciam a aprendizagem e aqueles que a impedem. Essa discussão fez com que os alunos, antes desconhecidos entre si, soubessem mais a respeito dos colegas de classe e de seus objetivos em estar em um curso de licenciatura. Muitos já são bastante proficientes, alguns têm um conhecimento mediano da língua e, nessa turma em especial, cinco eram iniciantes.

Nas aulas seguintes, a professora explicou para a turma o que era autonomia, o fato de que todos os falantes proficientes de uma língua adicional não a aprenderam apenas indo para a aula e fazendo os exercícios prescritos pelo professor, fato comprovado pelas narrativas anteriormente discutidas. Ela deixou bem claro aos alunos que o processo pode ser protagonizado por eles mesmos ao assumirem o controle sobre os processos 
cognitivos, o conteúdo e o gerenciamento de sua aprendizagem (BENSON, 2001). Esse controle provém da reflexão sobre o que já sabem, o que almejam saber e como fazê-lo.

Depois de decorridas cerca de oito horas de aula, a professora explicou-lhes que iriam ser os primeiros a utilizar um jogo que havia sido preparado pelo grupo de pesquisas liderado por ela. Ela disse a eles que o objetivo do jogo era auxiliá-los a refletir sobre seus processos de aprendizagem e lhes perguntou se queriam participar do experimento. Ante a resposta positiva da classe, deu-se a implementação.

A professora contou no primeiro dia com o auxílio de duas alunas do último ano do curso, ambas participantes do grupo de pesquisas sobre autonomia e que já conheciam o jogo desde as fases primeiras de seu desenvolvimento, que foi sempre discutido no grupo de pesquisa. Assim, eram três os possíveis "mestres" para liderar os grupos.

Após a explicação das regras, foi distribuído o modelo em uma folha de papel para que cada aluno ali anotasse a data em que cada dimensão fosse percorrida. Foi explicado a eles que todos deveriam percorrer todas as dimensões no decorrer do semestre e que a avaliação de seu aproveitamento na disciplina seria feita por meio de três coletas do $\mathrm{CA}^{3}$ ou $\mathrm{PA}^{3}$. Os baralhos de cada dimensão foram dispostos em carteiras na frente da sala e os alunos se levantaram para, diante do painel, escolherem a dimensão que queriam trabalhar por primeiro.

Coincidentemente, formaram-se três grupos, ficando a professora e as duas alunas auxiliares, uma em cada grupo, exercendo o papel de "mestres" nessa primeira rodada. Na figura a seguir, pode-se ver como ocorria essa dinâmica na sala de aula. 


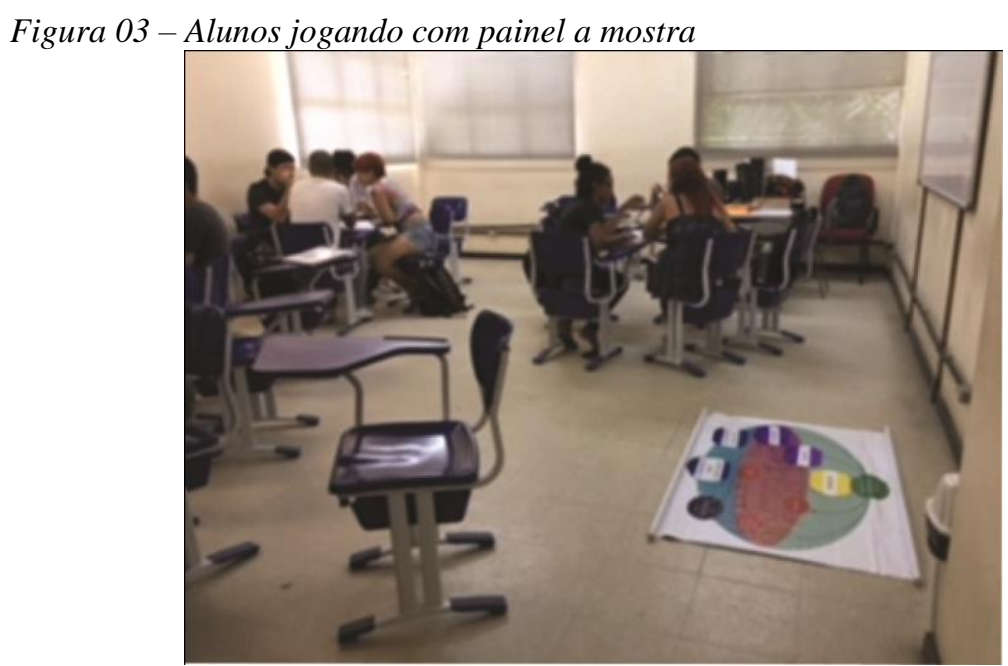

Fonte: As autoras

O "mestre", em cada grupo, instigava a discussão, sempre procurando estender a fala de cada aluno, fazendo com que ele detalhasse as ações que desenvolvia. Também era papel do mestre fazer com que todos tomassem a palavra, distribuindo os turnos de fala, quando necessário. $\mathrm{O}$ mestre também perguntava aos alunos se poderiam experimentar em seu processo de aprendizagem algumas das estratégias empregadas pelos colegas.

As discussões seguiam animadas, com a participação efetiva de todos nos pequenos grupos. Os alunos fizeram também anotações em suas fichas de rodada que, posteriormente, embasariam a pequena narrativa a ser feita na ficha, ao final de cada dimensão. Essas fichas de dimensão comporiam a base do $\mathrm{CA}^{3}$ ou $\mathrm{PA}^{3}$.

$\mathrm{Na}$ aula seguinte dedicada ao jogo, os alunos já haviam aprendido a dinâmica de funcionamento e naturalmente escolheram a mesma ou outra dimensão. Nessa ocasião, a professora contou com o auxílio de uma mestranda - integrante do grupo de pesquisas e conselheira linguageira -, que no momento preparava uma dissertação sobre o diálogo no aconselhamento. Como os alunos já podiam também exercer o papel de mestres, a professora deixou a mestranda em um dos grupos e designou alunos para serem os mestres dos demais. Quatro grupos se formaram nesse dia, com composições, em geral diferentes, daquelas do primeiro dia. Cada 
partida durava cerca de uma hora, assim, a professora ia mesclando o jogo com os conteúdos particulares da disciplina.

A partir da terceira aula dedicada ao jogo, os grupos eram formados, e seus próprios integrantes atribuíam a um colega do grupo a função de mestre. A professora orientou que o mestre deveria sempre ser alternado para que todos tivessem a oportunidade de exercer esse papel. Durante a rodada, ela circulava entre os grupos, oferecendo ideias, complementações e ouvindo o que os alunos diziam. Nessa ação, percebese o quanto do controle da aula foi cedido aos alunos. Essa é uma das funções do professor autonomizador (DAM, 2003). Ele precisa ceder seu controle sobre o que ocorre na sala e ensinar aos alunos que eles podem tomar decisões dentro e sobre o processo de aprendizagem.

Depois de algumas aulas, os próprios alunos arrumavam as carteiras, o próprio jogo e se organizavam rapidamente para jogar a dimensão que haviam escolhido no dia. Já ao final do semestre, com a complementação das dimensões por diferentes alunos, alguns tiveram que percorrer o trajeto em duplas ou até individualmente. No entanto, esse último caso foi raro.

Os nomes para o jogo foram surgindo já a partir da segunda rodada e foram sendo elencados no quadro pela professora. A turma decidiu, dentre as possibilidades, nomear o jogo de "Eu autônomo".

A próxima seção será dedicada à exposição de alguns dos resultados alcançados

\section{Resultados}

Nesta seção, discutiremos o fato de que a autonomização é um percurso individual, embora socialmente construído. Também demonstraremos como o jogo pode auxiliar os aprendentes a refletirem sobre seu próprio processo de aprendizagem, levando-os à conscientização de que devem ser protagonistas desse processo se quiserem ser bemsucedidos.

Talvez por ser uma experiência inédita, tanto para a professora quanto para os alunos, alguns destes demoraram um tempo para "entrar no jogo" e compreender o que se almejava com essa atividade. Outros, logo no início, já perceberam a riqueza do processo e o quanto poderiam alavancar seu processo de aprendizagem ao jogar. 
Quais alunos se encaixavam em qual grupo foi facilmente percebido ao longo das coletas do $\mathrm{CA}^{3}$ ou $\mathrm{PA}^{3}$. A explicação que antecedeu a primeira coleta foi extensa e detalhada. Muitos não sabiam o que colocar no seu caderno, nem o que era um portfolio. A maioria nunca tinha feito um portfolio e muito menos o compreendia como um possível instrumento de avaliação. A professora explicou do que se tratava e trouxe alguns exemplos de portfolios feitos por seus alunos para outros fins em turmas anteriores. Ela também se acostumou com os olhares incrédulos e confusos durante essas explicações e tranquilizava os alunos no sentido de que eles aprenderiam à medida que fizessem suas produções.

Para deixar claro o que era esperado deles, a professora explicitou os critérios e descritores por meio dos quais os $\mathrm{CA}^{3}$ ou $\mathrm{PA}^{3}$ seriam avaliados. Os critérios foram: 1) reflexão, 2) comprovação da reflexão e 3) indícios de autonomia. Para descrever a reflexão sobre sua aprendizagem, os alunos deveriam comentar sobre os pontos mencionados nas dimensões percorridas que eles já faziam e o que e como aprendiam com isso. Na comprovação dessa reflexão, eles deveriam incluir no $\mathrm{CA}^{3}$ ou $\mathrm{PA}^{3}$ exemplos de exercícios ou tarefas da disciplina de Inglês I - ou de outros contextos em que estudassem inglês - que suscitaram essa reflexão. Finalmente, para comprovar que eles demonstraram indícios de autonomia, eles deveriam incluir no $\mathrm{CA}^{3}$ ou $\mathrm{PA}^{3}$ atividades que eles tivessem feito por si sós, sem que um professor as tivesse demandado. Com esses critérios e descritores, a maioria dos alunos pode desenvolver seu caderno ou seu portfolio, ter prazer em experimentar esse novo (para eles) instrumento de avaliação e dar um passo em direção a sua autonomização.

A professora leu cada um dos $\mathrm{CA}^{3}$ ou $\mathrm{PA}^{3}$ dos alunos e fez comentários individualizados em qualquer trecho do documento. Quando entregue digitalmente, ela pediu que os alunos o fizessem em documento editável para que ela, usando uma cor diferente, incluísse seus comentários ao longo do texto. Quando entregue em papel, ela usava pequenos adesivos (post it) para apor suas observações. Em ambos os casos, ao final, ela comentava o trabalho de cada aluno mais extensamente e atribuía a eles o conceito. Eles obtiveram excelente se os três critérios fossem satisfatórios, bom se dois deles fossem cumpridos e regular se apenas um tivesse sido obedecido.

Gostaríamos de ressaltar aqui que um aluno iniciante deixou de entregar seu portfolio tanto na primeira quanto na segunda coletas. No entanto, ele era um aluno extremamente participativo, mas estava hesitante 
em preparar e entregar seu material. Quando, após a avaliação pela professora, os trabalhos eram devolvidos aos colegas e discutidos em pequenos grupos, ele observava tudo com olhar inquiridor. Esse é um aluno que demonstrou, nos testes de estilos de aprendizagem, ser extremamente reflexivo e não gostar muito, devido a seu caráter introspectivo, de trabalhar em grupos. A professora incitou-o a entregar seu portfolio para que ele pudesse ser aprovado na disciplina. No último dia de coleta, ele entregou um portfolio virtual de 30 páginas, cobrindo todas as dimensões do jogo e explicitando muito bem todos os critérios e descritores, mostrando e comprovando sua riquíssima trajetória de aprendizagem ao longo do semestre. Ele apenas demorava mais para entregar seu trabalho, só o fazendo quando se sentia totalmente satisfeito com o que podia fazer. Dentro da compreensão de que a autonomização é um processo com ritmos diferentes para cada aluno, ele recebeu, ao final do semestre o conceito excelente. Ou seja, esse aluno compreendeu o que é ser autônomo em sua aprendizagem e, por isso, mereceu seu conceito na disciplina.

Como resultado principal, pudemos perceber que o modelo dinâmico, que constitui a base desse jogo, visa, por meio da reflexão, a atingir dois objetivos. O primeiro é despertar seus usuários para os múltiplos aspectos que intervêm na sua aprendizagem; o segundo é leva-los a se tornarem cada vez mais atentos a esses aspectos a fim de serem capazes de identificar seus pontos fortes e reconhecer onde precisam de ajuda (TASSINARI, 2016). O percurso rumo à autonomia foi sendo percorrido ao longo das jogadas em conjunto com os colegas, com o auxílio da professora sem, no entanto, deixar de ser uma construção individual.

Com intuito de conhecer a influência do jogo, selecionamos dois portfólios que ilustram percurso realizado por dois aprendentes iniciantes, chamados aqui de Lorena e Gustavo, e que nos permitem observar, de pontos de vista diferentes, o processo de autonomização desses jogadores. Inicialmente, como vemos nos excertos abaixo, algumas dimensões surpreenderam os jogadores:

(1) "Até então nunca havia percebido que era necessário fazer um gerenciamento disso" (Lorena - Lidar com meus sentimentos).

(2) "Eu nunca na minha havia, na minha vida, parado para pensar em meus sentimentos com relação a minha aprendizagem" (Gustavo - Lidar com meus sentimentos).

Ser autônomo implica, entre outros aspectos, ser consciente dos fatores que podem contribuir para o sucesso de sua aprendizagem e 
daqueles que, ao contrário, podem retardá-la. Despertar a conscientização de aprendentes, jogadores no nosso contexto, é um dos objetivos bem como a razão do desmembramento das várias dimensões e componentes da autonomia do modelo proposto por Tassinari. Isso possibilita aos aprendentes/jogadores, como a professores e a conselheiros, compreender sua importância, como vemos nos depoimentos abaixo:

(3) Eu pude refletir e perceber o quão importante é saber lidar com os sentimentos bons e ruins quando se está aprendendo uma língua (Lorena - Lidar com meus sentimentos).

(4) $[\ldots]$ ao passar por esta dimensão, eu pude perceber, de maneira mais clara, a influência que meus sentimentos causavam na minha aprendizagem de línguas (Gustavo - Lidar com meus sentimentos).

Conhecer as dimensões e componentes foi apenas o primeiro passo para o funcionamento do jogo. O passo seguinte foi compreender, em cada rodada, de que maneira eles influenciavam sua aprendizagem, como lidavam com ela, o que sabiam, o que precisavam saber e melhorar e, principalmente, como fariam isso.

Constituído de todas as fichas de rodada e de conclusão de dimensão preenchidas ao fim de cada uma delas, no portfólio de Lorena temos o registro do passo a passo das descobertas, das reflexões e das decisões tomadas pela jogadora, proporcionando, assim, uma visão processual do desenvolvimento de sua autonomia. Gustavo, por sua vez, chamou atenção das pesquisadoras ao recusar-se a entregar seu portfólio durante as duas primeiras coletas e, ao produzir, no fim da disciplina, depois da insistência da professora, um portfólio virtual no qual reflete retrospectivamente sobre todas as dimensões do jogo, possibilitando, dessa maneira, a observação do produto de suas reflexões.

Considerando as especificidades dos portfólios analisados, procederemos a comentar cada um separadamente.

\subsection{O processo de autonomização de Lorena}

Lorena percorreu nove das dez dimensões do jogo preenchendo as respectivas fichas de rodada e de conclusão de dimensão. Constatamos em seus depoimentos que as discussões realizadas em grupo contribuíram positivamente para a compreensão e avaliação de seu desempenho: 
(5) Através do jogo pude fazer uma análise do que me motiva: minha história, minha mãe e também perceber que estou aprendendo inglês (Motivar-se).

(6) Vejo que estou muito limitada. Percebo que não tenho um plano de aprendizagem e não consigo organizar tempo e local para minha aprendizagem (Estruturar conhecimento).

A formulação dos descritores das competências de cada componente em termos de "eu consigo" e o preenchimento da ficha de rodada - quando o jogador sistematiza o resultado de suas reflexões, dizendo não apenas o que sabe fazer, mas "como" o faz - constituem um momento privilegiado de autoavaliação. Autoavaliar-se não significa apenas fazer um julgamento de suas competências e progressos; se assim fosse, estaríamos no âmbito de uma avaliação da aprendizagem realizada pelo aprendente (TASSINARI, 2015). Na verdade, autoavaliar-se implica apreciar e compreender o que se faz e como se faz, trata-se de uma avaliação para e na aprendizagem, uma avaliação com objetivos formativos que visa a levar os aprendentes a serem cada vez mais atentos aos fatores que contribuem ou prejudicam sua aprendizagem.

Ainda a esse respeito, acompanhamos o amadurecimento das reflexões de Lorena a respeito de suas competências, habilidades e hábitos de aprendizagem, como ilustram as respostas dadas à pergunta "O que você já sabe fazer? (Se possível, dizer como o faz)" da ficha de rodada:

(7) Estou alerta a meus sentimentos; reconheço sentimentos particulares que me estimulam como a alegria e satisfação ao finalizar uma tarefa [...] Reconheço sentimentos que me impedem ou bloqueiam (Lidar com meus sentimentos).

(8) Eu consigo preparar um plano de aprendizagem com referência a um objetivo provisório; passos concretos de uma tarefa, materiais de aprendizagem (Planejar).

Em (7) e (8), realizadas no início das jogadas, temos autoavaliações pouco aprofundadas nas quais a jogadora apenas diz o que sabe fazer, basicamente transcrevendo o conteúdo das cartas do jogo. O mesmo não ocorre nos excertos (9) e (10):

(9) Eu consigo reconhecer o que me impede de completar uma tarefa [...] Busco manter o meu plano de aprendizagem e por isso tenho que monitorá-lo diariamente; reflito sobre minha aprendizagem e monitoro minha aprendizagem, esse ano comecei um caderno de inglês I e já percebo de outubro até o momento, eu tive uma evolução. Sei que 
monitorando, preparando o local e tempo sou capaz de muito mais (Monitorar).

(10) Avalio minhas competências linguageiras sozinha, com outros, com o quadro europeu (eu nem fazia parte e agora me considero A1), com uma prova. De modo geral consigo observar que antes não conseguia ler um pequeno texto do livro e já consigo pronunciar certas palavras. Noto uma evolução, consigo avaliar meu progresso (Avaliar).

Como observamos em (9) e (10), além de se autoavaliar, Lorena reflete sobre os descritores, ilustrando suas apreciações com ações implementadas e reconhecendo progressos e conquistas alcançadas ao longo do jogo.

A conscientização resultante da autoavaliação de competências, habilidades e hábitos de estudo seria inócua se não resultasse na tomada de decisões referentes a aspectos que precisam ser regulados. Constatamos, como ilustram os excertos (11) e (12), que, ao longo do semestre, Lorena previa estratégias cada vez mais alinhadas com as metas que estabelecia no momento de responder à segunda questão da ficha de rodada $(\mathrm{O}$ que você quer aprender a fazer? Como você pretende atingir essa meta?).

(11) A prioridade é aprender a organizar tempo e local para minha aprendizagem; escolher diferentes métodos e estratégias; elaborar um plano de aprendizagem; planejar tempo e local para aprendizagem. Esses pontos para mim são fundamentais, pois meu horário e desgaste não me permitem estudar da forma como preciso. (Estruturar conhecimento).

(12) Eu quero aprender a avaliar a minha aprendizagem. Eu reflito nesse processo, porém quero dedicar um pouco mais de tempo para avaliar como alcancei um objetivo, se as tarefas foram adequadas, se dediquei tempo, quanto tempo, se procrastinei, enfim verificar (Avaliar).

Embora não haja uma questão na ficha de conclusão de dimensão voltada especificamente para a descrição das ações efetivamente implementadas a partir das metas estabelecidas, verificamos que, no portfólio de Lorena - quando descreve aquilo que "já sabe fazer" nos outros componentes - as decisões tomadas foram colocadas em prática. Os excertos (13) e (14), extraídos das fichas de rodada e de conclusão, exemplificam essas ocorrências:

(13) Que quero aprender a preparar um plano de aprendizagem como referência ao meu objetivo, às condições que eu tenho para trabalhar (tempo disponível), meu estilo de aprendizagem e forma de avaliação a 
qual serei submetida (Planejar, Ficha de rodada).

(14) [...] eu refleti e observei que a melhor forma para eu me planejar seria através de uma lista semanal de atividades. Não quis criar um planejamento tão extenso para eu não me sobrecarregar mentalmente [...]Na primeira semana de janeiro dei o $1^{\circ}$ passo e separei o horário e o local de estudo (para completar a tarefa) e iniciei meus estudos através de vídeos, de gramática, pronúncia e outros [...] Na segunda semana a professora trouxe uma reflexão sobre falar, escrever, ver e ouvir. Então estou adaptando o planejamento para trabalhar uma competência a cada dia a fim de ter habilidade em todas elas (Planejar, Ficha de conclusão de dimensão).

Percebemos, nos excertos acima, indícios de escolha de materiais mais adequados e de planejamento, em comparação com as manifestações anteriores. Isso ilustra, a nosso ver, como o processo de autonomização de Lorena foi bem-sucedido e como o jogo a auxiliou a encontrar um caminho.

\subsection{O processo de autonomização de Gustavo}

Diferentemente de Lorena, cujo processo de autonomização acompanhamos a partir das fichas de rodada e de conclusão de dimensões, Gustavo entregou seu portfólio apenas na última coleta. Nele o jogador apresenta e ilustra, em 30 páginas, o produto das reflexões realizadas ao longo do jogo. Assim, para cada uma das dez dimensões o jogador identifica aspectos das componentes que precisam de ajustes, reflete sobre eles, seleciona, implementa e avalia as estratégias utilizadas para atingir suas metas.

As avaliações e reflexões realizadas por Gustavo são particularmente ricas no que tange à descrição de critérios e descritores. $\mathrm{O}$ olhar retrospectivo que lança sobre o seu percurso de aprendizagem permite que, ao efetuar esse distanciamento, ele o objetive, compreenda e o descreva de forma clara e objetiva, como vemos abaixo:

(15) [...] fiquei surpreso ao perceber que o que eu imaginava ser, uma pessoa que sabe gerenciar sua aprendizagem, na verdade não era bem assim [...] Eu sempre escolhia uma hora aleatória e o lugar de mais sossego para estudar, o que eu precisasse estudar, e nunca vi problema nenhum nisso [...] Percebi que, por mais sossegado o lugar, sempre aparecia alguém que me tirasse à concentração [...] e que escolher uma hora aleatória [...] não era realmente produtivo, ou seja, eu estava me 
O jogo "Eu Autônomo" como um instrumento de reflexão...

sabotando e nem percebia (Dimensão Gerenciar aprendizagem).

(16) Eu consigo estudar mesmo estando chateado, triste, com raiva. Estudar nessas situações até me ajuda, pois eu acabo por me concentrar no assunto e esqueço, por um momento, o que estou passando (Dimensão Lidar com sentimentos).

Ao percorrer novamente as dimensões que analisou ao longo do jogo, Gustavo percebe a relação entre elas:

(17) [...]pude perceber que "monitorar", assim como todas as outras dimensões, está ligado a "avaliar", costumo disser que elas andam de mãos dadas (Dimensão Monitorar).

(18) Essa é a dimensão que segura, praticamente, na mão de todas as outras. Estruturar conhecimento significa analisar e organizar cada fase de aprendizagem expostas até agora (Dimensão estruturar conhecimento).

Reconhecer a relação entre as dimensões, perceber como uma influencia e complementa a outra, revela que Gustavo alcançou os objetivos do jogo com a conscientização dos componentes que intervêm no seu processo de aprendizagem, bem como a capacidade de apreciá-los. Ao contrário de Lorena (provavelmente pelo fato de, diferentemente da colega que preenchia as fichas durante as jogadas, ter organizado seu portfólio como um relato de sua trajetória ao longo do semestre) Gustavo descreveu e comprovou as ações que implementou:

(19) Para poder resolver esse problema de local e hora, decidi fazer da seguinte forma: para o local, resolvi estabelecer um lugar fixo onde eu pudesse me concentrar e, também não sofrer interrupções para não quebrar a linha de pensamento durante os meus estudos (Dimensão Gerenciar aprendizagem)

(20) Para resolver a estagnação do meu "speak" [...]Estou gravando coisas que eu já aprendi a expressar até agora, como falar de mim, dos meus amigos, do meu bairro, etc., e escutando para poder perceber se eu estou errando em algo (Dimensão Monitorar).

Além de descrever as estratégias que utilizava, Gustavo as comprovava tanto com imagens - das lâmpadas trocadas de seu quarto e da cadeira nova que ganhou de sua tia aos aplicativos e sites que usava para estudar a língua - quanto com os quadros que elaborou para organizar seus estudos, como mostramos abaixo: 
Figura 04 - Cronograma de atividades de Gustavo

\begin{tabular}{|c|c|c|c|c|c|c|c|c|c|}
\hline & $\begin{array}{c}5: 20 \mathrm{~h}- \\
6: 30 \mathrm{~h}\end{array}$ & $\begin{array}{c}6: 30 \mathrm{~h}- \\
7: 40 \mathrm{~h}\end{array}$ & $\begin{array}{c}7: 40 \mathrm{~h}- \\
9: 20 \mathrm{~h}\end{array}$ & $\begin{array}{l}9: 20 \mathrm{~h}- \\
12: 50 \mathrm{~h}\end{array}$ & $\begin{array}{c}12: 50 \mathrm{~h} \\
- \\
14: 00 \mathrm{~h}\end{array}$ & $\begin{array}{l}14: 00 \mathrm{~h}- \\
16: 00 \mathrm{~h}\end{array}$ & $\begin{array}{c}16: 00 \mathrm{~h}- \\
18: 00 \mathrm{~h}\end{array}$ & $\begin{array}{c}18: 00 \\
h- \\
19: 00 \\
h\end{array}$ & $\begin{array}{l}19: 10 \mathrm{~h} \\
\overline{20: 10 h}\end{array}$ \\
\hline Segunda & & $\begin{array}{l}\text { Acordar } \\
\text { /preparar } \\
\text { para ir para } \\
\text { UFPA. }\end{array}$ & $\begin{array}{c}\text { Transpo } \\
\text { rte até a } \\
\text { UFPA }\end{array}$ & $\begin{array}{l}\text { Horário } \\
\text { de Aula }\end{array}$ & $\begin{array}{c}\text { Retorno } \\
\text { para } \\
\text { casa }\end{array}$ & $\begin{array}{l}\text { Almoço e } \\
\text { descanso }\end{array}$ & $\begin{array}{l}\text { Estudar } \\
\text { aprender } \\
\text { aprender }\end{array}$ & $\begin{array}{l}\text { Tomar } \\
\text { um } \\
\text { cafezi } \\
\text { nho }\end{array}$ & $\begin{array}{l}\text { Estudar } \\
\text { inglês }\end{array}$ \\
\hline Terça & & $\begin{array}{l}\text { Acordar } \\
\text { /preparar } \\
\text { para ir para } \\
\text { UFPA. }\end{array}$ & $\begin{array}{c}\text { Transpo } \\
\text { rte até a } \\
\text { UFPA }\end{array}$ & $\begin{array}{l}\text { Horário } \\
\text { de Aula }\end{array}$ & $\begin{array}{c}\text { Retorno } \\
\text { para } \\
\text { casa }\end{array}$ & $\begin{array}{c}\text { Almoço e } \\
\text { descanso }\end{array}$ & $\begin{array}{c}\text { Estudar } \\
\text { linguístic } \\
\text { a }\end{array}$ & $\begin{array}{l}\text { Tomar } \\
\text { um } \\
\text { cafezi } \\
\text { nho }\end{array}$ & $\begin{array}{l}\text { Estudar } \\
\text { inglês }\end{array}$ \\
\hline Quarta & & $\begin{array}{c}\text { Transport } \\
\text { e até a } \\
\text { UFPA }\end{array}$ & $\begin{array}{l}\text { Horário } \\
\text { de Aula }\end{array}$ & $\begin{array}{l}\text { Horário } \\
\text { de Aula }\end{array}$ & $\begin{array}{c}\text { Retorno } \\
\text { para } \\
\text { casa }\end{array}$ & $\begin{array}{l}\text { Almoço e } \\
\text { descanso }\end{array}$ & $\begin{array}{l}\text { Estudar } \\
\text { inglês }\end{array}$ & $\begin{array}{l}\text { Tomar } \\
\text { um } \\
\text { cafezi } \\
\text { nho }\end{array}$ & $\begin{array}{l}\text { Estudar } \\
\text { inglês }\end{array}$ \\
\hline Quinta & & $\begin{array}{c}\text { Acordar } \\
\text { /preparar } \\
\text { para ir para } \\
\text { UFPA }\end{array}$ & $\begin{array}{c}\text { Transpo } \\
\text { rte até a } \\
\text { UFPA }\end{array}$ & $\begin{array}{l}\text { Horário } \\
\text { de Aula }\end{array}$ & $\begin{array}{c}\text { Retorno } \\
\text { para } \\
\text { casa }\end{array}$ & $\begin{array}{l}\text { Almoço e } \\
\text { descanso }\end{array}$ & $\begin{array}{c}\text { Fazer } \\
\text { trabalhos } \\
\text { que tiver } \\
\text { pendente }\end{array}$ & $\begin{array}{l}\text { Tomar } \\
\text { um } \\
\text { cafezi } \\
\text { nho }\end{array}$ & $\begin{array}{l}\text { Estudar } \\
\text { inglês }\end{array}$ \\
\hline Sexta & & $\begin{array}{l}\text { Acordar } \\
\text { preparar } \\
\text { para ir para } \\
\text { UFPA }\end{array}$ & $\begin{array}{c}\text { Transpo } \\
\text { rte até a } \\
\text { UFPA }\end{array}$ & $\begin{array}{l}\text { Horário } \\
\text { de Aula }\end{array}$ & $\begin{array}{c}\text { Retorno } \\
\text { para } \\
\text { casa }\end{array}$ & $\begin{array}{l}\text { Almoço e } \\
\text { descanso }\end{array}$ & $\begin{array}{l}\text { Estudar } \\
\text { inglês/ } \\
\text { espanhol }\end{array}$ & $\begin{array}{l}\text { Tomar } \\
\text { um } \\
\text { cafezi } \\
\text { nho }\end{array}$ & $\begin{array}{l}\text { Estudar } \\
\text { inglês }\end{array}$ \\
\hline Sábado & & $\begin{array}{c}\text { Acordar as } \\
7: 30 \mathrm{~h}\end{array}$ & \multicolumn{3}{|c|}{$\begin{array}{l}\text { A partir das } 8: 30 \text { até ao } \\
\text { 12:00h fazer trabalhos que } \\
\text { ficaram pendentes durante a } \\
\text { semana }\end{array}$} & \multicolumn{4}{|c|}{$\begin{array}{l}\text { Tirar o resto do dia para descansar ou } \\
\text { sair (sair para relaxar); etc.. }\end{array}$} \\
\hline Doming & & $\begin{array}{l}\text { escanso } \\
\text { rie, sair }\end{array}$ & a horário & $\begin{array}{l}\text { a se cum } \\
\text { etc. }\end{array}$ & rir (a não & em ex & es); ass & $m f$ & ou \\
\hline
\end{tabular}

Fonte: Portfolio de Gustavo

\section{Conclusão}

Compreendendo autonomia como uma "capacidade multidimensional" (BENSON, 2001, p.47), construída socialmente em sala de aula na interação com professores e colegas, este trabalho objetivou verificar os impactos do jogo "Eu autônomo" no despertar para a aprendizagem autônoma de iniciantes da graduação em Língua Inglesa. O jogo constituía uma novidade tanto para os alunos que, pela primeira, vez eram convidados a refletir sobre a sua aprendizagem, quanto para a professora, que também pela primeira vez implementava o jogo em sua disciplina. Percebemos como todos os envolvidos aprenderam a jogar e como se apropriaram rapidamente das regras, a ponto de na terceira rodada os próprios alunos desempenharem os papéis de mestre, antes assumidos pela professora e por membros do grupo de pesquisa.

A análise dos portfólios selecionados possibilitou-nos observar mais de perto, de dois pontos de vista diferentes, como dois jogadoresaprendentes vivenciaram essa experiência e o impacto dela em sua 
aprendizagem. Por um lado, pudemos acompanhar, passo a passo, o amadurecimento das reflexões, inicialmente pouco aprofundadas, de Lorena e a escolha de estratégias cada vez mais adequadas às metas que estabelecia. A cada rodada, com a ajuda dos colegas e orientada pelos descritores do jogo, vimos como a jogadora se conscientizava e se envolvia ativamente em sua aprendizagem, manifestando comportamentos cada vez mais autônomos, ilustrando o que pede Benson (2011) quando preconiza que se deve construir a autonomização por meio de ações concretas. Por outro lado, o portfólio de Gustavo nos permitiu lançar um olhar retrospectivo sobre esse processo. Em seus relatos, percebemos como o jogador lidou com cada dimensão: descobrindo, observando, analisando (tanto as dimensões quanto a relação entre elas), implementando ações (regulando-as quando necessário) e avaliando os resultados.

Concluímos, então que, ao envolver os jogadores-aprendentes em um processo de descoberta, conscientização, reflexão e regulação das dimensões que compõem a autonomia, o jogo atuou como um guia nos primeiros passos em direção à autonomia de Lorena e Gustavo. Assim, à medida que se continue usando o jogo em sala de aula ou em centros de autoacesso, poder-se-á verificar se ele é, de fato, uma ferramenta para apoiar o processo de autonomização.

\section{Referências}

BENSON, Phil. Teaching and researching autonomy in language learning. $1^{\text {a }}$ Ed. Harlow: Longman, 2001.

BENSON, Phil. Teaching and researching autonomy in language learning. $2^{\mathrm{a}}$ Ed. Harlow: Longman, 2011.

BENSON, Phil.; COOKER, Lucy. (Orgs.) The applied linguistic individual: Sociocultural approaches to identity, agency and autonomy. Bristol: Equinox, 2013.

DAM, Leni. Developing learner autonomy: the teacher's responsibility. In: LITTLE, David; RIDLEY, Jennifer; USHIODA, Ema (Ed.). Learner Autonomy in the Foreign Language Classroom. Dublin: Autentik, 2003. p. 135-146. 
FRANCO, Cláudio P. Autonomia na aprendizagem de inglês: um estudo de caso com nativos digitais sob as lentes do caos e da complexidade. 2013. 201f. Tese (Doutorado em Linguística Aplicada) - Faculdade de Letras, Universidade Federal de Minas Gerais, Belo Horizonte, 2013.

HOLEC, Henri. Autonomy in foreign language learning. Oxford: Pergamon, 1981.

KASDORF, Luiza. Jogos no ensino de língua estrangeira. 2013. 58f. Monografia (Especialização em Ensino de Línguas Estrangeiras Modernas) - Universidade Tecnológica Federal do Paraná, Curitiba, 2013.

PAIVA, Vera L. M. O. Autonomia e complexidade. Linguagem \& Ensino, v. 9 , n. 1, 2006. p. 77-127.

TASSINARI, Maria Giovanna. Assessing Learner Autonomy: a Dynamic Model. In: EVERHARD, Carol J.; MURPHY, Linda. (Eds.). Assessment and Autonomy in Language Learning. New York: Palgrave McMillan, 2015. p. 64-88.

TATZL, Dietmar. A systemic view of learner autonomy. In: GKONOU, Christina; TATZL, Dietmar; MERCER, Sarah (Orgs.) New directions in language learning psychology. Graz: Springer, 2016. p. 39-54.

VAN LIER, L. The Ecology and Semiotics of Language Learning. A Sociocultural Perspective. Boston: Kluwer, 2004.

Anexo A

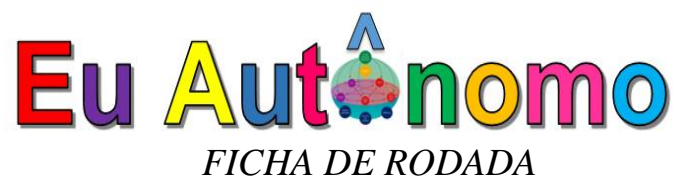

Jogador (a):

Data da rodada:

Caro jogador,

Por favor, responda às questões abaixo ao fim da rodada justificando suas respostas. 
O jogo "Eu Autônomo" como um instrumento de reflexão...

Na rodada de hoje, eu avaliei a minha capacidade de:

Eu analisei as cartas $n^{\mathbf{o}}$ :

1 - ) O que você já sabe fazer? (Se possível, dizer como o faz).

2 - ) O que você quer aprender a fazer? Como você pretende fazer isso?

3 - ) O que não é importante para você? Por quê? 
Anexo B

\section{Eu Autînomo \\ FICHA DE CONCLUSÃO DE DIMENSÃO}

Jogador (a):

Dimensão explorada:

Data da conclusão da dimensão:

Caro jogador,

Por favor, escreva uma breve narrativa relatando como esta atividade contribuiu para a sua aprendizagem.

Inclua também suas impressões sobre como você contribuiu para a aprendizagem de seus parceiros de jogo.

Esta ficha fará parte do seu Caderno de Anotações de Aprendizagem Autônoma $\left(\mathrm{CA}^{3}\right)$ ou Portfolio de Anotações de Aprendizagem Autônoma $\left(\mathrm{PA}^{3}\right)$.

Recebido em: 05/06/2019

Aceito em: 22/08/2019

Title: The game "Autonomous Me" as a reflection tool for learning foreign languages 